\title{
Self, Belonging and Social Change
}

\section{Vanessa May}

University of Manchester, UK

\begin{abstract}
One of the central interests of sociology is the relationship between self and society, and in particular how social change affects individuality, constraining or liberating the selves that we can be. This article proposes that because a sense of belonging plays a central role in connecting the person to the social, it can act as a window into studying the relationship between social change and the self. Furthermore, belonging offers a complex person-centred and dynamic approach that avoids reifying social structures, but rather depicts them as actively lived. A focus on belonging thus allows a dynamic examination of the mutual influence between self and society, and of how everyday practices are both regulated and creative, and hence generative of social change.
\end{abstract}

\section{Keywords}

belonging, self, social change

\section{Introduction}

One of the central interests of sociology is the relationship between self and society. This article examines whether the concept of belonging can bring something new to sociologists' attempts to understand the link between the self and the social, in particular the effects of social change on our selves. This article begins by examining two sociological accounts on social change that have come to dominate the discipline. The first posits that modernity has led to psychosocial fragmentation, while the second maintains that the conditions of modernity have increased people's capacity for reflexivity. This article addresses two central weaknesses of these theses. First, their view of the past as 'fixed' and stable compared with a fluid and unpredictable present is misguided (Burkitt, 2004; Williams, 1977). Second, they depict 'society' as an entity entirely separate from the 'self', and, in so doing, prioritize the role of social structures in their accounts of social

\footnotetext{
Corresponding author:

Vanessa May, Department of Sociology, Arthur Lewis Building, University of Manchester,

Oxford Road, Manchester MI3 9PL, UK.

Email: vanessa.may@manchester.ac.uk
} 
change. However, as Simmel (1950) and Elias (2001) have pointed out, self and society are mutually constitutive and therefore cannot be examined separately.

In light of these criticisms of the psychosocial fragmentation and extended reflexivity theses, the self is here taken as the starting point in order to examine the interconnections between social structures and the self, as well as the impact that social change has on our selves. In doing so, I draw inspiration from the sociology of everyday life and the sociology of personal life. The former examines how people engage with pre-existing social structures in both regulated and creative ways (e.g. De Certeau, 1984), while the latter understands human life as comprised of complex, interconnected spheres, and selves as connected to other people as well as culturally and socially embedded (Smart, 2007).

Furthermore, I propose that belonging is an apt concept for studying this relationship between the self and society for four reasons. First, it is person-centred; second, it takes us into the everyday where the official and unofficial spheres interact; third, it allows us to view the relationship between self and society as complex; and fourth, its dynamic nature allows us to examine social change. But first, I briefly outline the key elements of the two dominant sociological accounts on the effects that social change has on our selves.

\section{Sociology on Social Change}

The first storyline that seems to repeatedly surface within sociology is one depicting the evils of social change, wreaking havoc on individual people and communities alike. To name just a few of the most famous, we have Marx's (e.g. Marx and Engels, 1977[1845]) account of how the forces of capitalism had alienated people not only from society but also from themselves. Some decades later, Tönnies (1963[1887]) offered his narrative of the shift from the cozy and dependable Gemeinschaft to the rather less comforting Gesellschaft, followed by Durkheim's (1984[1893]) version, which was similar in tone, focusing on the shift from mechanistic to organic solidarity that in its extreme leads to anomie. Fast-forward to the latter half of the 20th century, and we encounter theorists such as Riesman (1961), Lasch (1978), Sennett (1998), Putnam (2000) and Furedi (2004) who have all offered similarly gloomy accounts of modernity, warning us of the dire psychological consequences of the loss of traditions and old certainties that is turning us into other-directed, self-obsessed, helpless and fragmented persons, which in turn is eroding trust, social cohesion and community.

These are but a sample of works that are part of what Adams (2007) terms the psychosocial fragmentation thesis. According to Frow, this virtually theological discourse on modernity characterizes contemporary life as 'the loss of significant totality, the fall into repetition' (2002: 632). Such nostalgic accounts that juxtapose contemporary society with the world we have lost and that we hope to redeem have also been readily picked up in popular debates.

A quite different story is offered by the now equally canonical extended reflexivity thesis that highlights the liberating effects of social change. According to Giddens (1991), as our lives have been disembedded from tradition and old contexts, the self has become a reflexive project no longer determined by social position. Consequently, people now face both the new freedoms and the new challenges or uncertainties that this reflexivity entails. Similarly, Beck (1992) has argued that the loss of old certainties 
means that people are left to craft their own biographies. Beck is, however, more cautious than Giddens in his pronouncements regarding the freedom for maneouvre that people have and points out that with increased institutionalization and standardization of, for example, the educational system and the labour market, our lives are now structured according to new institutional biographical patterns (Beck, 1992: 131-2). This account of extended reflexivity has also clearly resonated with both sociologists and the general public.

The aim of this rather crude overview of social theory, which glosses over the tensions and complexities included in the theorists' work, is to point to two related aspects that seem prevalent in both accounts of social change. First, past societies tend to be presented as more fixed than present ones. Second, 'society' and 'individual' are depicted as two separate spheres, emphasizing the role that social structures play in shaping our lives. These points are addressed in more detail below.

\section{Fixed Social Structures of the Past Versus a Fluid Personal Sphere in the Present?}

What unites the two sociological accounts that were briefly described above is their depiction of the past and the present as distinctly different. The past is characterized by stable and clearly identifiable social structures that strongly determined individual lives, which were consequently more predictable than contemporary lives (Williams, 1977). In contrast, when social theorists turn their gaze to the society of their day, they tend to see constant change that unsettles any such moorings, securities or certainties. As a result, they can end up depicting the present as fluid and in the making, and as somewhat chaotic and formless (Burkitt, 2004: 220).

Adam critiques the dualism of such 'before-and-after analyses of fixed states, established retrospectively' and proposes that tradition has not been replaced by 'reflexivity, disorder, flux and uncertainty', but that these co-exist, which is why it is their 'mutual implication' that should be the focus of social theory (1996: 135). Thompson (1996) argues that such analyses are also based on the misconception that traditions are fixed and pre-given, when in fact they are always open to change and flexible. In sum, traditions have not disappeared, but rather remain important features of contemporary societies though their nature and role may have shifted (1996: 94).

Such romanticized interpretations of the past are partly based on the optical illusion created by viewing past societies through social structures, which are easily seen as fixed and stable, while theorists' vantage point into the present is often through the personal, which appears malleable (Burkitt, 2004). This leads me onto the second critique of the individualization and psychosocial fragmentation theses: they distinguish 'social structures' and 'the personal' as two separate and inherently different spheres. Social structures are depicted as semi-permanent fixtures that exist over and above people, imposed upon them and determining who they can be (Burkitt, 2004: 212; Williams, 1977). Conversely, the personal is equated with 'everyday life', which in turn is constructed in essentializing terms, creating a myth of 'ordinary' everyday life (Sandywell, 2004: 174). Contrary to this perceived difference between 'social structures' (the official sphere) and 'the personal' (the unofficial sphere), they are in fact 
more similar than such views allow; interdependent and permeable, each affected by the other (Burkitt, 2004; Sandywell, 2004; Williams, 1977).

\section{Self and Society as Mutually Constitutive}

It is here that I turn to Simmel (1950) and Elias (2001) who both proposed that because neither self nor society can be understood independently of each other, sociologists should be focusing on the relationship between them. Simmel (1950: 9-10) depicted society as an event, as something that individuals $d o$, rather than a concrete substance, and consequently he used the term 'sociation' in preference to 'society'. Thus he presented interaction as a key element of the social, and argued that sociologists should not confine themselves to studying large social formations alone because less conspicuous forms of relationship and interaction are also significant (1950: 9). In addition, this article argues that society is also made up of how people relate to their material environment as well as to more abstract or symbolic notions such as 'society', shared cultural norms, traditions and values.

Elias similarly warned against thinking of either society or the individual as more important than the other, because society could not exist without individuals, while individuals do not exist separate from society. Instead, he urged sociologists to examine the relationship between them:

... to understand them [individuals and society] it is necessary to give up thinking in terms of single, isolated substances and to start thinking in terms of relationships and functions. (2001: 19)

Simmel proposed that the 'interaction between individuals is the starting point of all social formations' (1990: 174) and that 'society' comes about as the result of some actions becoming permanent and crystallized as definable and consistent structures such as state, family and class that assume a logic and independence of their own (1950: 9). Thus social structures should not be viewed as reified entities but rather as sedimented practices resulting from fixing 'in geographical space and in codified language the relational forms and activities of the past' (Burkitt, 2004: 220). This fixing can have both material manifestations (e.g. the distribution of wealth in society) and intangible consequences (e.g. ways of thinking or social norms) (Young, 2005: 20).

When sociologists abstract the social, however, they debar it as relevant or significant to the immediate (Williams, 1977: 129). Yet our everyday practices occur in the context of and are affected by these sedimented ways of thinking and doing things (Burkitt, 2004; De Quieroz, 1989). Although we recognize social forms more easily when they are articulated and explicit, and therefore appear 'fixed' and permanent, they only become a part of social consciousness if they are 'lived, actively, in real relationships' (Williams, 1977: 130). These social structures are meaningful in people's lives because they 'constitute the historical givens in relation to which individuals act and which are relatively stable over time' (Young, 2005: 20).

Although social structures are the aggregate result of many individual interactions and change as the result of 'the confluence of many individual actions within given institutional relations' (Young, 2005: 20), we can rarely if ever reduce them to the conscious 
intentions of one person or group of people (Elias, 2001; Young, 2005: 20). Bourdieu speaks in similar terms of the 'structuring structure' of 'habitus' as 'collectively orchestrated without being the product of the orchestrating action of a conductor' (1977: 72). Furthermore, social change cannot be predicted because it is the combined result of individual people reacting to new situations in, to some degree, idiosyncratic rather than completely patterned and predictable ways (Bourdieu, 1977: 73; Elias, 2001: 63-4). There thus exists a constant and complex loop between individual (inter)action and social change, both affecting each other.

\section{Personal Lives in the Everyday}

Such an understanding of the nature of social change requires a dynamic approach that examines the creative ways in which people interact with pre-existing social structures. Two sociological approaches, the first focusing on everyday life, and the second on personal life, offer us the conceptual tools to do so.

When trying to understand the relationship between self and society, one of the best places to start is in everyday life, where the official and the unofficial spheres of activity and thought intersect (Burkitt, 2004). An interest in the everyday means focusing on 'the very close, the familiar, and the habitual' (Harrison, 2000: 497) as well as on a form of consciousness that is habitual and distracted (Felski, 2002: 607). Everyday life, however, encompasses both routine repetition of past behaviours as well as creative actions that help change what is regarded as 'commonplace' (McCracken, 2002: 147). Consequently, the sociology of everyday life views social reality not as a static or an a-historic finished product but rather as emergent, as something that is forever fluid, dynamic and 'almostnot-quite' (Harrison, 2000: 501; Sandywell, 2004: 165). Furthermore, a focus on the everyday allows us to view social change not simply as a top-down process generated by 'extraordinary' events but as something that also results from our mundane 'ordinary' activities and from the tactics (De Certeau, 1984) that people use to negotiate their way through or around social structures.

This article also borrows conceptual tools from the sociology of personal life as developed by Smart (2007). The term 'personal', which Smart uses instead of the more atomistic 'individual', highlights the connectedness and social embeddedness of people's lives; people are 'embedded in both sedimented structures and the imaginary' (2007: 28-9). This interest in the role that 'traditions' and 'social structures' on the one hand and creativity on the other play in our lives is something that the sociology of personal life shares with the sociology of everyday life, and further helps overcome the distinction between 'the unofficial' and 'the official' spheres. Personal life is 'lived in many different places and spaces [... ] and it forms a range of connections' (Smart, 2007: 29). In addition, a personal life approach focuses on life projects, and is therefore able to portray a sense of motion in people's lives, brought about by events such as unemployment or processes such as ageing that transform our lives.

Belonging is here presented as a concept that allows for a person-centred, dynamic and complex approach and that understands people as active participants in society. In the remainder of this article, four aspects of belonging which make it particularly useful for studying the interrelatedness of self and social change are discussed in some detail. 
First, a focus on belonging allows us to study the links between 'the self' and 'society' from the point of view of the person and, second, to examine how people engage with social structures in their everyday lives. Third, a sense of belonging is complex, encompassing our relational, cultural and sensory connections. Fourth, the concept of belonging lends itself well to the study of social change because our experiences of belonging are dynamic and sensitive to changes. In the ensuing discussion, examples from empirical studies on belonging from a wide range of disciplines including sociology, geography, cultural studies and design studies are offered as illustration.

\section{Belonging Links the Person with the Social}

Belonging is here defined as a sense of ease with oneself and one's surroundings. Miller proposes that belonging is 'the quintessential mode of being human [... ] in which all aspects of the self, as human, are perfectly integrated - a mode of being in which we are as we ought to be: fully ourselves' (2003: 218), while Baumeister and Leary argue that the need to belong is 'a powerful, fundamental, and extremely pervasive motivation' (1995: 497). Belonging is thus a crucial aspect of being a person: it is 'fundamental to who and what we are' (Miller, 2003: 217). Belonging involves a process of creating a sense of identification with one's social, relational and material surroundings (Miller, 2003), or 'of recognising - or misrecognising - the self in the other' (Leach, 2002: 287). As Weeks says: 'Identity is about belonging, about what you have in common with some people and what differentiates you from others' (1990: 88).

Thus belonging plays a role in connecting individuals to the social. This is important because our sense of self is constructed in a relational process in our interactions with other people as well as in relation to more abstract notions of collectively held social norms, values and customs. These social origins of the self have been the particular focus of the symbolic interactionist school of thought. The Meadian 'me' assumes a set of social attitudes and is consequently able to imagine how a 'generalised other' would see its actions and to evaluate these in light of the group's norms (Mead, 1934), while the Goffmanian self employs (unwritten) social rules to present a moral self (Goffman, 1959). Bourdieu's theory of habitus also encompasses these social rules of engagement. He talks about mastery of 'the game'within a particular social field - knowing what to do, how and when (Bourdieu, 1977: 161, 1979: 250-1, 330).

A sense of belonging is indeed partly achieved on the basis of knowing these unwritten rules and being able to conduct oneself in an 'acceptable' manner before others (Fortier, 2000). We can make claims for belonging by citing shared understandings of who 'we' are and how 'we' behave (Bell, 1999b; Fortier, 2000). Yet what is lacking in the accounts above is a sense of where these collective rules come from, or how they develop. As Shotter (1993) argues, a sense of belonging is not built merely on the existence of a collectively shared culture, but requires also the right to participate in the development of the 'living tradition' or the reflexive arguments of that society:

... that is, arguments about what should be argued about, and why. [... ] to be able to feel that in doing so one is contributing to one's own world, one must be able to participate in the argument. (Shotter, 1993: 193) 
This is the intersubjective element that Bottero proposes is missing from Bourdieu's concept of habitus, which is characterized by an 'abstract emphasis on objective structural relations' (2009: 401). Murphy further develops these arguments by criticizing Bourdieu for privileging 'relations between social positions at the expense of exploring the substance of these positions' and for neglecting 'the emotional content of familial and communal relations' (forthcoming: 105-6). As Skeggs's (1997) and Sayer's (2005) work shows, people experience their social position and their intersubjective ties as drenched with emotion and morality. 'Belonging' differs from 'habitus' because it is a relational concept that necessarily focuses on social interaction and intersubjectivity, and the emotional content of these.

Intersubjectivity is important exactly because the collective understandings on which we build our sense of belonging are not merely 'the result of individuals internalising their shared conditions in the same fashion' but are rather negotiated accomplishments (Bottero, 2009: 413-14). For example, the women interviewed by Fenster (2005: 227-8) in Jerusalem and London expressed the right to participate in decision-making and the right to choose, for example, where to live, how to decorate one's home or how to use public space, as necessary in order to achieve a sense of belonging. The South African people who had experienced forced removals during Apartheid expressed similar sentiments when interviewed by McEachern (1998): not having the right to choose where to live had meant that they had lost part of their identity and their sense of belonging in the city:

These people were [... ] forced into a racialised kind of suburbia, a mode of living and an identity which was not of their own choosing. And in doing so they lost a significant element of their identity as South Africans. They lost their right to determine their own identities. (1998: 514)

The quote from McEachern above exemplifies how inclusion in the reflexive arguments of a society or in collective decision-making is not an automatic right in any society; some people find themselves on the margins or excluded. Because shared cultures and values, or understandings of who 'we' are and what 'we' stand for, are the result of struggles over representation and membership, they tend to reflect power structures and serve the interests of those in power (e.g. Miller, 2003; Probyn, 1996; Shotter, 1993; Weedon, 2004; Williams, 1977: 115-17). There exist, in other words, hierarchies of belonging, and not everyone is allowed to belong. Belonging is therefore more than just an individual feeling - it is also a hotly contested political issue with collective consequences (Weedon, 2004). For example, in contemporary Britain, ethnic minority people may find their claims for British identity rejected (Eade, 1994; Ifekwunigwe, 1999; Weedon, 2004). Belonging can thus have both an emotional component of 'feeling at home' or 'yearning for a home', and a political element of claim-making for space and for recognition (Bell, 1999a; Miller, 2003; Scheibelhofer, 2007: 321).

\section{Belonging in the Everyday}

A sense of belonging is based on everyday habits (Jackson, 1983: 334). Belonging is an appropriate concept for studying the relationship between social change and the self precisely because it brings us into the territory of the everyday where the 'official' and 
'unofficial' spheres intersect. This is the phenomenological world of Schütz's (1962) 'natural attitude', of everyday practices that, although constitutive of social order, remain largely in the realm of the taken for granted and the 'seen but unnoticed' (Garfinkel, 1967: 180). Belonging can therefore be understood as an everyday mode of being that is largely unconscious or not the focus of conscious thought (Felski, 2002). In other words, one of the ways in which a sense of belonging can emerge is if we can go about our everyday lives without having to pay much attention to how we do it.

Conversely, a disruption in our everyday environment can make us feel uprooted (Jackson, 1983: 328). When our expectations of the everyday are not met, when we cannot go about our mundane tasks as we are accustomed to, and when we become consciously aware of our habitual ways of being and doing, we can awaken to a feeling of not belonging. It is from this lack of fit that a sense of unease, of not belonging, emerges. This sense of not belonging will be examined in more detail later on in the article.

Once again there is a similarity between belonging and Bourdieu's notion of habitus. According to Bourdieu (1979: 171-2), our habitus fits a specific social field and as long as we remain in this field we are not necessarily aware of our habitus, but rather, it feels 'natural' to us. What the concept of belonging allows us to do that habitus does not is to understand how people can be embedded in a familiar everyday world yet feel that they do not belong there. As discussed above, belonging is an intersubjective experience that necessarily involves other people. We make claims for belonging which others either reject or accept, and therefore, mere familiarity with a place, a group of people or a culture is not enough for us to gain a sense of belonging.

Bourdieu's analysis has further been critiqued for being structurally deterministic: because habitus are viewed as the result of structure, they have no movement of their own - habitus only change as a result of changing structures (De Certeau, 1984: 57-8). Conceptualizing belonging as rooted in the everyday allows for a dynamic picture of two-way influence between structures and everyday habits (cf. Burkitt, 2004). Although social structures help shape who we are, our actions are not completely determined by them; we do have scope for microresistant tactics that contribute to socio-structural change (cf. Felski, 2002: 612; De Certeau, 1984: 40).

\section{Belonging is Multidimensional}

The third reason why belonging lends itself to the study of the interlinking of self and social change is that it is a multidimensional experience that interweaves many aspects of our being in the world. This is crucial because the self is also multifaceted, comprising age, gender, ethnicity, sexuality, religion, education, occupation, hobbies, cultural tastes, and more. Furthermore, during the course of our lives we come into contact with many different people, social contexts and places. Consequently, few of us feel a sense of belonging merely to one group, culture or place but rather experience multiple senses of belonging. For example, people of mixed heritage or migrants may experience manifold, and at times contradictory, senses of belonging (Ifekwunigwe, 1999). Eade (1994: 386) found that second-generation Bangladeshi Muslims living in Britain could formulate complex national, regional and religious belongings. Many saw their different forms of belonging as competing, and reconciled this by constructing 'composite, hierarchically 
ordered identities' (Eade, 1994: 391). In her study of an Italian immigrant community in London, Fortier uses the phrase 'migrant belongings' in order to capture 'the productive tension that results from the articulation of movement and attachment, suture and departure, outside and inside, in identity formation' (2000: 2). She argues that immigrant populations vacillate between 'national identity' and 'émigré identity', producing a 'cultural citizenship that is grounded in multilocality' (2000: 97).

A further multidimensional aspect of belonging is that, in addition to people and collective ideas, we also construct a sense of belonging to places and material objects (Downing, 2003: 213; Fortier, 2000; Savage et al., 2005). In this aspect, habitus once more covers some of the same terrain as belonging. In her study of Italian immigrants, Fortier (2000) uses Bourdieusian terms to describe how people experience a sense of belonging in spaces where there is a correspondence between their body hexis and the social field. Such habitual spaces feel familiar to us and we know instinctively what to do and how to behave just by stepping into them (e.g. churches).

What the concept of belonging offers, however, that habitus does not sufficiently take into consideration is an understanding of how our connections with our natural and built environments are sensory (Friedmann, 2002). We come to know the world through our sensuous embodied experiences of touch, sound, smell and taste that help us achieve 'a holistic way of understanding three-dimensional space' (O'Neill, 2001: 3). From a phenomenological point of view, it can be argued that our knowledge of the world 'is not just a matter of thought about the world, but stems from bodily presence and bodily orientation in relation to it, bodily awareness' (Tilley, 1994: 14, emphasis in original). As we regularly walk or move through places, we create our own spatial routes through them (Bendiner-Viani, 2005: 462). By means of such habitual timespace routines, or 'place-ballets' (Seamon, 1980), we become familiar with the contours of the landscape, as well as with its typical smells, sights and sounds (O'Neill, 2001). In De Certeau's (1984) terms, we 'territorialise' space by moving through it and in doing so we make space 'our own'. In other words, we build a sense of belonging in the world based on the meanings we give our environment by moving through and engaging with it (Leach, 2002: 286).

This engagement with and sense of belonging to place is fundamental to our sense of self (Leach, 2002: 286). Tilley proposes that our individual and cultural identities are 'bound up with place' and that we create a sense of self 'through place' (1994: 15). When identifying with a place, we mirror ourselves with our surroundings: we 'introject' the external environment into us, while we also 'project' or read ourselves onto the external world (Leach, 2002: 288). In sum, we go through a process of 'making sense of place, developing a feeling of belonging and eventually identifying with that place' (Leach, 2002: 292), and in this process we come to understand who we are, both as individuals and as a group of people:

The place acts dialectically so as to create the people who are out of that place. These qualities of locales and landscapes give rise to a feeling of belonging and rootedness and a familiarity, which is not born just out of knowledge, but of concern that provides ontological security. They give rise to a power to act and a power to relate that is both liberating and productive. (Tilley, 1994: 26) 
Tilley's argument about the link between belonging and the ability to act echoes that of Shotter (1993), that is, that belonging is not merely a state of mind but is bound up with being able to act in a socially significant manner that is recognized by others.

\section{Belonging is the Result of Dynamic Practices}

We have so far seen how a sense of belonging is achieved by being and doing in the world. This means that belonging is not a static state as indicated by Heideggerian notions of 'dwelling' and that territorialization is not necessarily about fixed roots, but about something more transitory and fluid (Leach, 2002: 286). Belonging can in other words be depicted as a trajectory through time and space (de Certeau, 1984). Our sense of belonging changes over time, partly in response to changes in our self. For example, becoming a parent can lead to a person developing a stronger sense of belonging to a locality (Fenster, 2005; Savage et al., 2005). Parents find themselves engaging both in new routines such as taking children to the playground, nursery or school, and new interactions with other parents and with teachers, which serve to connect them to a locality in a novel way (Savage et al., 2005: 54). Fenster (2005: 223) found similarly in her study that, after becoming mothers, women started using their local neighbourhood and its services such as shops and of course schools more intensely, and consequently felt a stronger sense of belonging or attachment to their area.

Our relational and cultural surroundings are also likely to undergo changes, which further contribute to shifts in our sense of belonging. Savage and colleagues (2005), for example, found that 'born and bred' residents of an area could experience a sense of not belonging if the sociodemographic profile of the area changed, for example if newcomers represented a different class or lifestyle. Furthermore, material transformations are an important part of social change, as witnessed in any major city, such as Manchester, where hundreds of years of industrial and social developments have left their mark on the physical contours of the city (Edensor, 2007). Any significant changes in our material surroundings will have an impact on our sense of belonging: as old forms of belonging such as urban architecture disappear or decay and new infrastructures are built, people are faced with having to make new connections, re-building their sense of belonging (Adams et al., 2007; Edensor, 2007).

Belonging is, in other words, not a given or something that we accomplish once and for all. Because the world and the people in it, including ourselves, are constantly undergoing change, belonging is something we have to keep achieving through an active process (Bell, 1999a: 3; Miller, 2003: 223; Scheibelhofer, 2007). Thus belonging offers an apt window into studying the interconnectedness of social change and the self - as the world around us changes, so does our relationship to it.

\section{Is Belonging an Ideal State?}

Belonging is of course a concept that for many people is laden with positive connotations. If belonging is understood as a sense of ease with one's surroundings, then arguably not belonging can be characterized as a sense of unease. In other words, our sense of 
'ontological security' (Giddens, 1991) is shaken as our immediate social context becomes less predictable or comfortable for us, and we no longer feel that we 'fit' with our surroundings. Most people would probably assume this ontological insecurity to be an undesirable state. For example, Shotter argues that being excluded from the language and reflexive arguments of a society 'is to live in a world not one's own' (1993: 195), which in turn can have a damaging effect on our sense of self (cf. Weedon, 2004).

Failing to identify with a place can also have negative consequences, such as placepanic where "we confront the imminent possibility of there being no place to be or to go', feel without place and estranged, and experience symptoms such as homesickness, disorientation, depression, desolation, or 'a sense of unbearable emptiness' (Casey, 1993: x). Casey points out that displacement and losing a connection with place is not solely the experience of those in exile, but in one shape or other all of us in today's 'speed-bound era' will feel it at various times in relation to our locality, city, region, culture or the world. According to Casey (1993: 307), such 'place-alienation' has a profound effect on people's sense of who they are. An alteration in place leads to an alteration in self, and those who are alienated from place may feel 'other than' themselves (Casey, 1993: 308).

A health warning is however in order at this point, lest we start idealizing belonging and arguing that not belonging is inherently harmful. A feeling of not belonging need not always be experienced negatively. For many of us, there exists a tension between wanting to be similar to and belong with others, and wanting to be unique and different from others (Elias, 2001; Simmel, 1971). More importantly, this tension can be productive. Indeed, some people seek a sense of not belonging for example by changing place through travel (Casey, 1993: 308-9), perhaps in order to 'broaden their minds'. It is at the moment when dispositional habitus is disrupted that reflexivity is awakened (Bottero, 2010: 8), which can also be understood as something akin to Lefebvre's (2002) 'moments' or Benjamin's (1999) 'shock experiences' that disrupt the smooth flow of everyday experience and of the taken for granted. Such fractures or joins can make us take note of our surroundings in a new and potentially productive way by allowing us to realize the 'rich and manifold possibilities that are presented to us at given historical conjunctures' (Gardiner, 2004: 243) and to see 'what could be' rather than just 'what is' (McCracken, 2002: 151).

In other words, a sense of not belonging can open up new possibilities of, for example, political action if we become conscious of the fact that the routine paths we have so far traversed are not the only possible ones. Indeed, some identities such as the Quebecois identity may be constructed on the margins or outside of dominant belongings (Probyn, 1996; Stychin, 1997). Stychin (1997: 33-5) further argues that the questioning of borders and membership by groups such as non-heterosexuals can be conducive to the development of 'deep diversity' where identities are not predetermined or totalizing but rather flexible and open to multiple belongings. Such resistance to belonging has also led to the development of new narratives of identity, such as narratives of lesbian identity, which have provided people with 'new material possibilities and social positions' (Duggan, 1993). Not belonging does not in other words have to have purely negative consequences, just as belonging is not necessarily a positive thing or an ideal state. 


\section{Conclusion}

This article has been engaging with the question of what people's everyday sense of belonging to their relational, cultural and material contexts might say about the interconnection between self and social change. I suggest that a focus on belonging provides an alternative to top-down structural theorizing that is characterized by a focus on how changes in society require people to adapt. In contrast, because of both its location in the everyday realities of people and its dynamic nature, belonging is a concept that allows us to examine the mutual interaction between social change and the self. The social is thus here defined not in terms of abstract social structures or a reified 'culture', but as something made up of the concrete, imagined or virtual relationships we have with people, collectives, the symbolic or abstract realm of 'cultures', objects, as well as our built and natural environments.

When viewed from the perspective of the everyday, the world does not change unbeknownst to us; we do not simply wake up one morning to find the world changed beyond recognition. Rather, change tends to be constant and incremental and is introduced piecemeal into our lives in the form of, for example, new technologies, new institutional practices, new forms of 'culture' and the changing requirements of the work-place. Furthermore, many theorists such as Marx, Durkheim, Giddens and Beck attribute a certain directionality and coherence to social change. However, as experienced by individuals, these changes do not appear to embody an overarching logic, and it is usually only with hindsight that we can identify a 'grand narrative' that allows us to understand different developments as interconnected and as part of a broader thing called 'social change' that has transformed our society in a particular direction. Simmel (1971) argues that it is because we are involved in many different groups and move through different spheres of life, and are consequently not shaped by one single force but by many, that we do not experience the wholeness of our lives but rather see our existence in such a fragmentary way (Levine, 1971: xxxviii). Similarly, we experience and respond to social change in a fragmentary fashion.

People's reaction to much of social change tends to therefore come in the form of gradual alterations in (some aspect of) their habits, routines and ways of thinking. We are faced with practical choices such as whether to start using a computer rather than a typewriter or whether to contact NHS Direct online rather than calling in at a doctor's surgery. Some choices are not ours to make - we might have to walk that extra mile to the nearest post office, start using electronic ticketing machines and swipe-cards, shop at a supermarket some miles distant if we no longer have access to a local butcher and baker, and so on. And by so adopting new ways of behaving and thinking, or resisting them, people contribute to further social transformations.

A focus on belonging allows us to examine who is allowed to take part in the reflexive arguments that contribute to changes in society, who is excluded from these and on which grounds, and the effects that such inclusion and exclusion have on people's sense of self. In other words, it is important to explore how a sense of belonging can be achieved and by whom. Belonging should, however, not be seen as automatically superior to not belonging. Not belonging can in fact be the more productive of the two in terms of social change if, as a result of questioning who 'we' are, people construct alternative identities 
and ways of life. Thus it is also crucial to examine who does not belong, and how experiences of not belonging help contribute to social change.

It is here that I return to Simmel's and Elias's arguments that self and society cannot be regarded as two separate entities. As Simmel (1950: 7-9) points out, if we view the world up-close, we see individual persons and their characteristics, but as we move further away our perspective changes and the individuals disappear, and what we see instead is society. We interpret this as seeing two separate entities, but both are in fact views of the same thing seen differently depending on our distance from it. Elias (2001) similarly points out that society should not be viewed as something separate from the relationships that constitute it. While the structural accounts of social change posit a distinction between the self and society comparable to the Cartesian inner-outer split, Simmel and Elias could be interpreted as saying that in as much as society consists of people, we are all 'out there' in society. To paraphrase Merleau-Ponty (1962), who argues that perception is a mode of being in the world rather than a question of spectating an external world, I argue that the self is a mode of being in society rather than something separate from society. We do not merely spectate a society or participate in it. We are in it, we are it. And one of the ways in which we experience this being in society is through our sense of belonging or lack thereof. A focus on belonging can thus offer a window into studying the complexities of the interrelationship between change on both the personal and the social level.

\section{Acknowledgements}

I am very grateful to the two anonymous reviewers for their helpful comments. I would also like to thank the audience members at the Turning Personal conference organized by the Morgan Centre for the Study of Relationships and Personal Life in 2009 for their positive encouragement of an early draft of this article.

\section{References}

Adam B (1996) Detraditionalization and the certainty of uncertain futures. In: Heelas P (ed.) Detraditionalization: Critical Reflections on Authority and Identity. Oxford: Blackwell, $134-48$.

Adams M (2007) Self and Social Change. London: Sage.

Adams M, Moore G, Cox T, Croxford B, Refaee M and Sharples S (2007) The 24-hour city: Residents' sensorial experiences. Senses \& Society 2(2): 201-16.

Baumeister RF and Leary MR (1995) The need to belong: Desire for interpersonal attachments as a fundamental human motivation. Psychological Bulletin 117(3): 497-529.

Beck U (1992) Risk Society: Towards a New Modernity. London: Sage.

Bell V (1999a) Performativity and belonging: An introduction. Theory, Culture \& Society 16(2): $1-10$.

Bell V (1999b) On speech, race and melancholia: An interview with Judith Butler. Theory, Culture \& Society 16(2): 163-74.

Bendiner-Viani G (2005) Walking, emotion, and dwelling: Guided tours in Prospect Heights, Brooklyn. Space and Culture 8(4): 459-71.

Benjamin W (1999) The Arcades Project (trans. Eiland H and McLaughlin K). Cambridge, MA: Belknap Press.

Bottero W (2009) Relationality and social interaction. British Journal of Sociology 60(2): 399-420. 
Bottero W (2010) Intersubjectivity and Bourdieusian approaches to 'identity'. Cultural Sociology 4(1): 3-22.

Bourdieu P (1977) Outline of a Theory of Practice. Cambridge: Cambridge University Press.

Bourdieu P (1979) Distinction: A Social Critique of the Judgement of Taste. London: Routledge.

Burkitt I (2004) The time and space of everyday life. Cultural Studies 18(2): 211-27.

Casey ES (1993) Getting Back Into Place: Toward a Renewed Understanding of the Place-World. Bloomington, IN: Indiana University Press.

De Certeau M (1984) The Practice of Everyday Life (trans. Rendall S). Berkeley, CA: University of California Press.

De Quieroz JM (1989) The sociology of everyday life as a perspective. Current Sociology 37(1): 31-9.

Downing F (2003) Transcending memory: Remembrance and the design of place. Design Studies 24: $213-35$.

Duggan L (1993) The trials of Alice Mitchell: Sensationalism, sexology, and the lesbian subject in turn-of-the-century America. Signs 18(4): 791-814.

Durkheim E (1984[1893]) The Division of Labor in Society (trans. Halls WD). New York: Free Press.

Eade J (1994) Identity, nation and religion: Educated young Bangladeshi Muslims in London's 'East End'. International Sociology 9: 377-94.

Edensor T (2007) Sensing the ruin. Senses \& Society 2(2): 217-32.

Elias N (2001) The Society of Individuals. New York: Continuum.

Felski R (2002) Introduction. New Literary History 33(4): 607-22.

Fenster T (2005) The right to the gendered city: Different formations of belonging in everyday life. Journal of Gender Studies 14(3): 217-31.

Fortier AM (2000) Migrant Belongings: Memory, Space, Identity. Oxford: Berg.

Friedmann J (2002) Placemaking as project? Habitus and migration in transnational cities. In: Hillier J and Rooksby E (eds) Habitus: A Sense of Place. Aldershot: Ashgate, 299-316.

Frow J (2002) 'Never draw to an inside straight': On everyday knowledge. New Literary History 33(4): 623-37.

Furedi F (2004) Therapy Culture: Cultivating Vulnerability in an Uncertain Age. London: Routledge.

Gardiner ME (2004) Everyday utopianism. Cultural Studies 18(2): 228-54.

Garfinkel H (1967) Studies in Ethnomethodology. Englewood Cliffs, NJ: Prentice-Hall.

Giddens A (1991) Modernity and Self-identity: Self and Society in the Late Modern Age. Cambridge: Polity.

Goffman E (1959) The Presentation of Self in Everyday Life. New York: Doubleday.

Harrison P (2000) Making sense: Embodiment and the sensibilities of the everyday. Environment and Planning D: Society and Space 18: 497-517.

Ifekwunigwe JO (1999) Scattered Belongings: Cultural Paradoxes of 'Race', Nation and Gender. London: Routledge.

Jackson M (1983) Knowledge of the body. Man (New Series) 18(2): 327-45.

Lasch C (1978) The Culture of Narcissism: American Life in an Age of Diminishing Expectations. New York: Norton.

Leach N (2002) Belonging: Towards a theory of identification with space. In: Hillier J and Rooksby E (eds) Habitus: A Sense of Place. Aldershot: Ashgate, 281-95.

Lefebvre H (2002) Critique of Everyday Life Vol. II: Foundations for a Sociology of the Everyday (trans. Moore J). London: Verso.

Levine DN (1971) Introduction. In: Levine DN (ed.) On Individuality and Social Forms. Chicago: University of Chicago Press, ix-Xv. 
McCracken S (2002) The completion of old work: Walter Benjamin and the everyday. Cultural Critique 52(Autumn): 145-66.

McEachern C (1998) Mapping the memories: Politics, place and identity in the District Six Museum, Cape Town. Social Identities 4(3): 499-521.

Marx K and Engels F (1977[1845]) The German Ideology, Part One (ed. and intro. Arthur CJ). London: Lawrence \& Wishart.

Mead GH (1934) Mind, Self and Society: From the Standpoint of a Social Behaviorist. Chicago: University of Chicago Press.

Merleau-Ponty M (1962) Phenomenology of Perception (trans. Smith C). London: Routledge \& Kegan Paul.

Miller L (2003) Belonging to country - A philosophical anthropology. Journal of Australian Studies 27(76): 215-23.

Murphy M (forthcoming) The ties that bind: Distinction, recognition and the relational. International Journal of Interdisciplinary Social Sciences 5(10): 103-16.

O’Neill ME (2001) Corporeal experience: A haptic way of knowing. Journal of Architectural Education 55(1): 3-12.

Probyn E (1996) Outside Belongings. New York: Routledge.

Putnam RD (2000) Bowling Alone: The Collapse and Revival of American Community. New York: Simon \& Schuster.

Riesman D (with Glazer N and Denney R) (1961) The Lonely Crowd: A Study of the Changing American Character. New Haven, CT: Yale University Press.

Sandywell B (2004) The myth of everyday life. Cultural Studies 18(2): 160-80.

Savage M, Bagnall G and Longhurst B (2005) Globalization and Belonging: The Suburbanization of Identity. London: Sage.

Sayer A (2005) The Moral Significance of Class. Cambridge: Cambridge University Press.

Scheibelhofer P (2007) His-stories of belonging: Young second-generation Turkish men in Austria. Journal of Intercultural Studies 28(3): 317-30.

Schütz A (1962) Collected Papers I: The Problem of Social Reality (ed. and intro. Natanson M). The Hague: Martinus Nijhoff.

Seamon D (1980) Body-subject, time-space routines, and place-ballets. In: Buttimer A and Seamon D (eds) The Human Experience of Space and Place. London: Croom Helm, 148-65.

Sennett R (1998) The Corrosion of Character: The Personal Consequences of Work in the New Capitalism. New York: Norton.

Shotter J (1993) Cultural Politics of Everyday Life. Buckingham: Open University Press.

Simmel G (1950) The field of sociology. In: Wolff G (ed. and trans.) The Sociology of Georg Simmel. New York: The Free Press, 3-25.

Simmel G (1971) The metropolis and mental life. In: Levine DN (ed.) On Individuality and Social Forms. Chicago: University of Chicago Press, 324-39.

Simmel G (1990) The Philosophy of Money, 2nd edn (trans. Bottomore T and Frisby D). London: Routledge.

Skeggs B (1997) Formations of Class and Gender: Becoming Respectable. London: Sage.

Smart C (2007) Personal Life: New Directions in Sociological Thinking. Cambridge: Polity.

Stychin CF (1997) Queer nations: Nationalism, sexuality and the discourse of rights in Quebec. Feminist Legal Studies 1(1): 3-34.

Thompson JB (1996) Tradition and self in a mediated world. In: Heelas P (ed.) Detraditionalization: Critical Reflections on Authority and Identity. Oxford: Blackwell, 89-108.

Tilley C (1994) A Phenomenology of Landscape: Places, Paths and Monuments. Oxford: Berg. Tönnies F (1963[1887]) Community and Society (trans. and ed. Loomis CP). New York: Harper \& Row. 
Weedon C (2004) Identity and Culture: Narratives of Difference and Belonging. Maidenhead: Open University Press.

Weeks J (1990) Coming Out: Homosexual Politics in Britain from the Nineteenth Century to the Present, rev. edn. London: Quartet Books.

Williams R (1977) Marxism and Literature. Oxford: Oxford University Press.

Young IM (2005) On Female Body Experience: 'Throwing Like a Girl' and Other Essays. Oxford: Oxford University Press.

Vanessa May is Lecturer in Sociology at the University of Manchester and a member of the Morgan Centre for the Study of Relationships and Personal Life. Her research interests include the self, belonging, lone motherhood, post-divorce parenting, intergenerational relationships, narrative analysis, biographical methods and mixed methods. Her work has been published in Sociology, Sociological Review, Women's Studies International Forum, International Journal of Social Research Methodology and Narrative Inquiry, among others. She is currently working on a book entitled Connecting Self and Society: Belonging in a Changing World, to be published by Palgrave.

Date submitted February 2010

Date accepted August 2010 